\title{
Infant Oral Health Care Concerning Education of Mothers - Part 1
}

\author{
Vidyasagar Mopagar1, Lehya Mounica Kadali², Vikranth Shetty ${ }^{3}$, Shridhar Shetty4, \\ Venkatesh Kodgi ${ }^{5}$, Shantanu Chaudhari ${ }^{6}$
}
1,2 Department of Paediatric and Preventive Dentistry, Rural Dental College, Loni, ${ }^{3}$ Department of Orthodontics, Tatyasaheb Kore Dental College and Research Centre, Kolhapur, Maharashtra, India, ${ }^{4}$ Department of Paediatric and Preventive Dentistry, Yogita Dental College, Khed, Maharashtra, India, ${ }^{5}$ Pearl Dental Specialty Clinic in Muscat, Oman. ${ }^{6}$ Department of Paediatric and Preventive Dentistry, Government Dental College and Hospital, Ahmedabad.

Infant oral health is one of the most overlooked aspects when it comes to the oral well -being of a child because many do not consider it to be of much significance. This is generally due to the misconception that children do not have teeth during this phase which leads to the conclusion that focus could be on other developmental aspects. There is also a deficit in the education of parents and family members. Knowledge of mothers is of extreme importance because they need to be well aware that a child's first dental visit should be between 6 - 12 months of age to maximize the preventive potential of fluorides, health literacy and dietary modifications.

Oral health, when integrated into primary medical care, can result in improved outcomes for children. A simple message of fluoride adequacy, dietary control of bottle use and sweet intake, oral hygiene, and regular dental visits cross professional barriers. This literature review aims to give mothers and family members access to information so that we can optimise the oral health of the infant.

\section{KEY WORDS}

Infant Oral Health, Knowledge, Attitude and Practice of Mothers, Anticipatory Guidance, Early Childhood caries.
Corresponding Author:

Dr. Lehya Mounica Kadali, Department. of Paediatric and Preventive Dentistry, Rural Dental College, Pravara Institute of Medical Sciences, Loni (B. K) E-mail:mounica1195@gmail.com

DOI: $10.14260 /$ jemds/2021/485

How to Cite This Article: Mopagar V, Kadali LM, Shetty V, et al. Infant oral health care concerning education of mothers - part 1. J Evolution Med Dent Sci 2021;10(30):2365-2368, $10.14260 /$ jemds/2021/485 DOI:

Submission 10-03-2021,

Peer Review 23-05-2021,

Acceptance 31-05-2021,

Published 26-07-2021.

Copyright (C) 2021 Viddyasagar Mopagar et al. This is an open access article distributed under Creative Commons Attribution License [Attribution 4.0 International (CC $B Y 4.0)]$ 


\section{BACKGROUND}

Any child that is younger than 12 months of age is defined as an infant. Generally, the words infant and oral health do not go together because most infants are born without teeth and remain that way throughout half of their infancy. This is a crucial time to instil habits, both negative and positive, that can possibly influence a person's future oral health just as overall health and prosperity into adolescence and adulthood. In the beginning of infancy, the oral cavity has only gum pads, the oral cavity sees the eruption of primary teeth. Keeping up healthy infant teeth, also alluded to as primary teeth, is basic to encourage appropriate growth and development in kids. Primary teeth are fundamental for eating, talking, and growth of the jaws. Dental caries and premature loss of child teeth can prompt serious issues in the permanent dentition. ${ }^{1}$ Hence, the primary aim of paediatric dentists at this age is to educate, motivate and encourage the parents to maintain good oral hygiene of the infants and make it a priority.

Unsatisfactory oral health and irregular feeding practices create an environment promoting the colonisation of bacteria. At the point when dental caries is being considered, a child's level of colonization of cariogenic microorganisms is directed by the mother's $S$. mutans level at the hour of transmission; suggesting that mother / parental figure's oral health status has an immediate impact on child's oral health. In addition, since mothers play a significant part in a child's life, their insight about a child's oral health will fundamentally affect the oral health status of children. An appropriate understanding of the mothers in regard to baby's oral health care will be gainful in decreasing the burden of dental caries in children. ${ }^{2}$ Infant oral health is the establishment whereupon schooling and motivation in regard to dental health and other preventive dental consideration are based on to have a dental disease free life. It is additionally an indispensable piece of the overall prosperity of an infant as he / she advances in age.

It incorporates the consideration of oral cavities and monitors the proper development of teeth. Deplorably, pregnant women, parents and caregivers of infants frequently don't get cutting-edge and exact schooling with respect to preventive oral and dental health care. ${ }^{3}$ Hence it is essential to stress the value of educating mothers, family members and caregivers about infant oral health care to ensure healthy growth and development of the child.

\section{INFANT'S MOUTH}

Teeth in an infant begin to form in utero. The primary dentition starts developing at around a month and a half to about two months of growth and dentition that starts to calcify before the finish of the first trimester. The greater part of the permanent dentition starts to form at roughly about five months of pregnancy, calcifying after birth. ${ }^{1}$ Although the primary teeth start to develop in utero, most babies do not have any teeth at birth. Oral microbial colonization of an infant's mouth begins shortly after birth. The infant's mouth consists just of gum pads in the pre-dentate stage, i.e., until around $6-7$ months old enough. At the point when teeth start to erupt into the oral cavity (as the infant enters the dentate stage), the colonization changes as the teeth present other hard tissue surfaces for colonization.

Impact from the mother / caregiver and siblings also play a part in the kind of colonization of an infant's mouth. Throughout early childhood or infant colonization by $S$. mutans is a main risk factor for early childhood caries and future dental caries. ${ }^{4}$ First securing of Streptococcus mutans affects the future oral health of infants. ${ }^{5}$ Infants may create $S$. mutans colonies from their colonized guardians. Mother - to youngster transmission is one of the essential wellsprings of transmission of $S$. mutans to an infant's mouth. ${ }^{3}$ This sort of transmission of $S$. mutans is likewise called as vertical transmission. ${ }^{6}$ Horizontal transmission is another significant method of transmission of $S$. mutans which happens when there is interpersonal contact like sharing of spoons, glasses between the infant and other members in their surroundings such as siblings, day care supervisors and other close contacts. Evidence for the horizontal type of microbe communication comes from multiple research debates which have evidence suggesting that toddlers in the same niche shared $S$. mutans colonies. $^{7}$ Consequently, vertical and horizontal communication of $S$. mutans require evaluation when considering risk factors for dental caries in an infant.

\section{PRENATAL ORAL HEALTH COUNSELLING}

Prenatal oral health counselling for parents is the first step to infant oral healthcare. Pregnancy is the earliest opportunity during which education about infant oral health can be provided. Pregnant ladies are particularly keen on their kids' general wellbeing and prosperity and the money saving advantages of preventive consideration as opposed to therapeutic medicines. ${ }^{8}$ As detrimental or inadequate maternal periodontal wellbeing has all the earmarks of being related with preterm labour, and low birth weight outcomes, pre-birth counselling and dental consideration for hopeful moms may bring about improved pregnancy results. 9,10

A pregnant woman should also be conscious of her own caries balance so that she can fully grasp what puts her at risk, her baby's health at risk, and what protective measures can give her newborn an early healthy start. ${ }^{11}$ Mothers are not always acquainted with the fact that their oral wellbeing status influences that of their children. "A mother's DMFS score, schooling, and nourishing habits are vital risk factors for the colonisation of caries-related microorganisms and early childhood caries (ECC). ${ }^{12}$

Ideally, optimisation of infant oral health starts prenatally. It advances with the supervision and counselling of the mother and kid, starting when the baby is around half a year old enough, with the eruption of the first tooth. ${ }^{13}$ of course, the mother's health during pregnancy has immediate and longterm implications on the baby's health. Oral health is no exception. Hypoplastic enamel on primary teeth generally has more to do with the mother's health during pregnancy rather than the infant's own health and well-being. Babies born prematurely or with meagre birth weight might also have hypoplastic enamel in both primary and permanent teeth as a result of disturbances in enamel formation. ${ }^{14}$ 


\section{DISCUSSION}

Literature suggests that early-in-life risk factors play a symbolic role as predictors of future dental caries in children. These risk factors include the extent of parental knowledge, attitude, and practices (KAP), oral hygiene status of the infant, medical history, oral medications and feeding habits. ${ }^{15-18}$

Thus it is crucial to fathom the causes and risk factors of poor infant oral health to avert the risk of early childhood caries later in life. Evidence collected from both global and Indian studies show that both expectant mothers and parents / caregivers of infants have poor KAP regarding infant feeding, weaning, and bottle feeding practices and cleaning of the mouth. ${ }^{19-22}$ Inappropriate infant feeding manners related to bottle feeding, breastfeeding and sweetened pacifiers / liquids may be other causes of early childhood caries (ECC) in the teeth of the infant. ${ }^{23}$ Bottle feeding in the night, with sweetened or sweet liquids, is a risk factor for ECC as it leads to a reduction of saliva, which in turn causes prolonged exposure to fermentable carbohydrates. ${ }^{23}$

Over here comes in the concept of anticipatory guidance at every stage of a child's development. Anticipatory guidance is the process of providing and implementing practical, developmentally appropriate information about children's health to make parents ready for the significant physical, emotional, and psychological milestones. 6,24

Anticipatory guidance encompasses three types of responsibilities: 6,8

1. Gathering data,

2. Establishing a curative alliance

3. Providing education and advice.

Infants having low birth weight and malnourished infants are at risk for the development of enamel hypoplasia. ${ }^{20,21,25}$ Enamel hypoplasia results in a rough enamel surface which leads to areas being more prone to plaque accumulation and resultant caries.25,26 Thus, expecting mothers should be advised to optimise nutrition during the third trimester of their pregnancy and the infant's first year of life when the enamel is undergoing maturation. ${ }^{8}$ Recent literature also reports a correlation between periodontitis in the mothers and preterm birth ${ }^{27}$ and between $S$. mutans levels in mothers and caries experience in their children. ${ }^{28}$

Anticipatory guidance for the pregnant mothers include the following: ${ }^{29,8,30}$

1. Providing education for the development and prevention of dental disease and also to demonstrate the usage of various oral hygiene products.

2. Counselling to instil precautionary attitudes and incentives among mothers for better infant oral health.

3. Spreading the information to pregnant women about pregnancy gingivitis and its association to preterm birth.

4. Visiting the dentist for regular check ups and restoration of all active decays as soon as possible to decrease chances of developing pregnancy gingivitis.

5. Practice eating healthy foods such as fruits, vegetables, grain products (especially whole grain), and dairy products (milk, cheese) during meals and snacks.

6. Limit eating between meals, i.e. frequency of the meals.

7. Limiting the amount and quantity of foods containing sugar.
8. Using a fluoridated toothpaste to brush teeth thoroughly twice a day and flossing daily.

9. Gargling every night with an alcohol free, over the counter fluoridated mouth rinse.

10. Avoiding cigarettes or chewing tobacco.

Prioritisation of infant feeding practices related to breastfeeding, bottle feeding and their timing of cessation must be considered. Infant formulas are acidogenic and therefore are cariogenic in nature. ${ }^{18,31}$

Recommendations for appropriate infant feeding practice behaviours include:8,20,32

- Avoid putting an infant to sleep with a bottle containing fermentable carbohydrates.

- At - will breastfeeding should be reduced after the first primary tooth begins to erupt, and other dietary carbohydrates are introduced.

- $\quad$ Parents should encourage the infant to drink from a cup as they approach their first birthday.

- At about 12 - 14 months of age, Infants should be weaned from the bottle.

- There should not be repetitive consumption of any liquid containing fermentable carbohydrates from a bottle or training cup.

Avoid in between meal snacks and prolonged exposure to foods and juice or other beverages containing fermentable carbohydrates.

\section{CONCLUSIONS}

Parent education and maximisation in knowledge, attitude and practices (KAP) concerning infant oral health care may yield extended - lasting benefits on an infant's oral health. Maternal/ caregiver KAP19-21 is an area where several schools of thought exist regarding infant nutrition, feeding practices and when to have the first dental visit.

Importance must be given to behavioural approaches when it concerns conditions such as ECC which begin early in life, then to the prevention of diseases and the promotion of healthy behaviour among mothers and their children. ${ }^{29}$ Cost effective and affordable health education, along with added motivation, has proven to be a valuable tool for promoting healthy behaviour in mothers and their children. ${ }^{33}$

Paediatric dentists, paediatricians and nutritionists have an interdisciplinary role concerning prenatal counselling with a common goal to provide the best oral and overall health for the new born and infant. New parents should be followed up on a regular basis to make sure that effective oral hygiene and food habits are being established through regular pre and perinatal parent counselling. ${ }^{34}$

Infant oral health forms a stable foundation for a long period of excellent oral health. The underlying focal point of infant oral health is counteraction, and all endeavours should be made to forestall and advance oral health at this critical stage of infancy.

Maternal training and stress on good oral health should also be aided at pre and perinatal stages to additionally forestall early colonisation of caries causing microbes. Considering that moms are particularly inspired by their health and the health of their kids, introducing a one of a kind 
and ideal second to proactively start a conversation about oral health related nurturing abilities with unmistakable expense and health benefits.

Financial or other competing interests: None.

Disclosure forms provided by the authors are available with the full text of this article at jemds.com.

\section{REFERENCES}

[1] Brecher EA, Lewis CW. Infant oral health. Pediatr Clin North Am 2018;65(5):909-21.

[2] Dutta B, Dhull KS, Samir PV, et al. Knowledge, attitude and practice of mothers towards infant oral healthcare. Int J Clin Pediatr Dent 2018;11(5):435-9.

[3] Fitzsimons D, Dwyer JT, Palmer C, et al. Nutrition and oral health guidelines for pregnant women, infants and children. Journal of the American Dietetic Association 1998;98(2):182-9.

[4] Berg JH, Slayton RL. Early Childhood Oral Health. John Wiley \& Sons 2009: p. 320.

[5] Thorild I, Lindau-Jonson B, Twetman S. Prevalence of salivary streptococcus mutans in mothers and in their preschool children. Int J Paediatr Dent 2002;12(1):2-7.

[6] Pinkham JR, Casamassimo PS. Pediatric dentistry: infancy through adolescence. Saunders 1999: p. 675.

[7] Mattos-Graner RO, Smith DJ, King WF, et al. Waterinsoluble glucan synthesis by mutans streptococcal strains correlates with caries incidence in 12-to 30month-old children. J Dent Res 2000;79(6):1371-7.

[8] Chandna P, Adlakha VK. Oral health in children guidelines for pediatricians. Indian Pediatr 2010;47(4):323-7.

[9] Dasanayake AP. Poor periodontal health of the pregnant woman as a risk factor for low birth weight. Ann Periodontol 1998;3(1):206-12.

[10] Kothiwale S, Panwar V. Poor periodontal health of pregnant women as a risk factor for preterm and low birth weight. Indian Journal of Dentistry 2011;2(4):12933.

[11] Featherstone JDB. The caries balance: contributing factors and early detection. J Calif Dent Assoc 2003;31(2):129-33.

[12] Sharma A, Sindhuja M, Subramaniam P. Association of salivary lipids and early childhood caries in an indian subpopulation: a preliminary study. J Clin Pediatr Dent 2019;43(6):393-7.

[13] Gomez SS, Weber AA. Effectiveness of a caries preventive program in pregnant women and new mothers on their offspring. Int J Paediatr Dent 2001;11(2):117-22.

[14] Ramos-Gomez FJ. Clinical considerations for an infant oral health care program. Compend Contin Educ Dent 2005;26(5 Suppl 1):17-23.

[15] Alaluusua S, Malmivirta R. Early plaque accumulation--a sign for caries risk in young children. Community Dent Oral Epidemiol 1994;22(5 Pt 1):273-6.

[16] Grindefjord M, Dahllöf G, Nilsson B, et al. Prediction of dental caries development in 1-year-old children. Caries Res 1995;29(5):343-8.
[17] Wendt LK, Hallonsten AL, Koch G, et al. Analysis of cariesrelated factors in infants and toddlers living in Sweden. Acta Odontol Scand 1996;54(2):131-7.

[18] Waltman K, Kahn A, Koency G. Alternative approaches to scoring: the effects of using different scoring methods on the validity of scores from a performance assessment. Psyc Extra Dataset 1998.

[19] Nagarajappa R, Kakatkar G, Sharda AJ, et al. Infant oral health: knowledge, attitude and practices of parents in Udaipur, India. Dent Res J (Isfahan) 2013;10(5):659-65.

[20] Nagaraj A, Pareek S. Infant oral health knowledge and awareness: disparity among pregnant women and mothers visiting a government health care organization. Int J Clin Pediatr Dent 2012;5(3):167-72.

[21] Shivaprakash PK, Elango I, Baweja DK, et al. The state of infant oral healthcare knowledge and awareness: disparity among parents and healthcare professionals. J Indian Soc Pedod Prev Dent 2009;27(1):39-43.

[22] Hoeft KS, Masterson EE, Barker JC. Mexican American mothers' initiation and understanding of home oral hygiene for young children. Pediatr Dent 2009;31(5):395404.

[23] Seow WK. Biological mechanisms of early childhood caries. Community Dent Oral Epidemiol 1998;26(1 Suppl):8-27.

[24] Lewis CW, Boulter S, Keels MA, et al. Oral health and pediatricians: results of a national survey. Acad Pediatr 2009;9(6):457-61.

[25] Seow WK, Humphrys C, Tudehope DI. Increased prevalence of developmental dental defects in low birthweight, prematurely born children: a controlled study. Pediatr Dent 1987;9(3):221-5.

[26] Horowitz HS. Research issues in early childhood caries. Community Dent Oral Epidemiol 1998;26(1 Suppl):6781.

[27] McGaw T. Periodontal disease and preterm delivery of low-birth-weight infants. J Can Dent Assoc 2002;68(3):165-9.

[28] Berkowitz RJ. Mutans streptococci: acquisition and transmission. Pediatr Dent 2006;28(2):106-9.

[29] Hobdell MH, Oliveira ER, Bautista R, et al. Oral diseases and socio-economic status (SES). $\mathrm{Br}$ Dent J 2003;194(2):91-6.

[30] Brambilla E, Felloni A, Gagliani M, et al. Caries prevention during pregnancy: results of a 30-month study. The J Am Dent Assoc 1998;129(7):871-7.

[31] Sheikh C, Erickson PR. Evaluation of plaque pH changes following oral rinse with eight infant formulas. Pediatr Dent 1996;18(3):200-4.

[32] American Academy on Pediatric Dentistry Council on Clinical Affairs. Policy on early childhood caries (ECC): unique challenges and treatment option. Pediatr Dent 2008;30(7 Suppl):44-6.

[33] Mohebbi SZ, Virtanen JI, Vehkalahti MM. Improvements in the behaviour of mother-child pairs following low-cost oral health education. Oral Health Prev Dent 2014;12(1):13-9.

[34] Chandna P, Adlakha VK. Infant oral health. Emerging Trends in Oral Health Sciences and Dentistry 2015. 